\title{
DESENVOLVIMENTO E MULTIPLICAÇÃO in vitro DE EMBRIÕES OBTIDOS POR EMBRIOGÊNESE SOMÁTICA DIRETA DE Coffea arabica L. CV. ACAIÁ CERRADO
}

\author{
DEVELOPMENT AND MULTIPLICATION in vitro OF EMBRYO OBTAINED BY \\ DIRECT SOMATIC EMBRYOGENESIS OF Coffea arabica L. CV. ACAIÁ CERRADO
}

\section{Alba Regina Pereira RODRIGUES ${ }^{1}$; Filipe Almendagna RODRIGUES ${ }^{2}$; Moacir PASQUAL ${ }^{3}$; José Magno Queiroz LUZ ${ }^{4}$}

1. Professora, Doutora, Centro Federal de Educação Tecnológica Celso Suckow da Fonseca, Valença, RJ, Brasil. albacefet@gmail.com; 2. Pós-doutorando em Agronomia/Fitotecnia, Universidade Federal de Lavras - UFLA, Lavras, MG, Brasil. filipealmendagna@yahoo.com.br; 3. Professor Titular, Doutor, UFLA, Lavras, MG, Brasil. mpasqual@dag.ufla.br; 4. Professor, Doutor, Universidade Federal de Uberlândia, Uberlândia, MG, Brasil. jmagno@umuarama.ufu.br.

RESUMO: Um importante método de multiplicação in vitro de plantas de Coffea é a embriogênese somática, que consiste no desenvolvimento de embrióides a partir de células haplóides ou somáticas possibilitando a micropropagação acelerada de clones superiores e a manutenção de híbridos interespecíficos. Entretanto, há poucos relatos da obtenção de embriogênese direta na espécie Coffea arabica. Objetivou-se com este trabalho estabelecer protocolo para desenvolvimento in vitro de embriões somáticos e produção de mudas de $C$. arabica cultivar Acaiá Cerrado. Avaliaram-se a influência de sacarose $\left(0 ; 30 ; 60 ; 90\right.$ e $\left.120 \mathrm{~g} \mathrm{~L}^{-1}\right)$ x BAP $\left(0 ; 2 ; 4\right.$ e $\left.8 \mathrm{mg} \mathrm{L} \mathrm{L}^{-1}\right)$ em embriões somáticos. No desenvolvimento das plântulas, testaram-se ANA $\left(0 ; 0,25 ; 0,5\right.$ e $\left.1 \mathrm{mg} \mathrm{L}^{-1}\right) \times \mathrm{GA}_{3}\left(0 ; 2,5 ; 5,0 ; 10\right.$ e $\left.20 \mathrm{mg} \mathrm{L}^{-1}\right)$ em brotações, com tamanho médio de 1 a $1,5 \mathrm{~cm}$, oriundas de embriões somáticos in vitro. Durante a etapa de indução de embriões, o experimento foi conduzido em sala de crescimento em condições de escuro e, na etapa de desenvolvimento dos embriões e plântulas, os explantes foram submetidos à irradiância em torno de $32 \mu \mathrm{M} \mathrm{m}^{-2} \mathrm{~s}^{-1}$ e fotoperíodo de 16 horas, à temperatura de $25 \pm 1{ }^{\circ} \mathrm{C}$. Na aclimatização, avaliou-se o efeito da presença e ausência de raízes em plântulas de cafeeiro oriundas de embriogênese somática direta. A adição de $90 \mathrm{~g} \mathrm{~L}^{-1}$ de sacarose e $2 \mathrm{mg} \mathrm{L}^{-1}$ de BAP ao meio de cultura proporciona melhor crescimento in vitro de embriões de cafeeiro. Utilizando-se $0,5 \mathrm{mg} \mathrm{L}^{-1}$ de ANA e $14,2 \mathrm{mg} \mathrm{L}^{-1}$ de $\mathrm{GA}_{3}$ obtém-se maior comprimento da parte aérea de brotações de $C$. arabica L. cv. Acaiá Cerrado. Conclui-se que é possível a obtenção de plântulas micropropagadas de $C$. arabica L. cultivar Acaiá Cerrado pela embriogênese somática direta. O enraizamento de brotações de cafeeiro cultivar Acaiá Cerrado ocorre simultaneamente ao processo de aclimatização.

PALAVRAS-CHAVE: Embriões somática. Cafeeiro. Aclimatização.

\section{INTRODUÇÃO}

O gênero Coffea, pertencente à família Rubiaceae, compreende mais de 100 espécies, que ocorrem naturalmente na África, Madagascar, Ilhas Comores, Ilhas Mascarenhas, subcontinente indiano, Ásia sul tropical, sudeste da Ásia e Australásia (DAVIS et al., 2006; DAVIS, 2010, 2011; DAVIS et al., 2011).

A espécie Coffea arabica se reproduz, preponderantemente, por autofecundação e é comercialmente propagado por semente. As estratégias de melhoramento genético visam ao desenvolvimento de cultivares altamente homozigotos para que, por sementes, sejam instalados lavouras uniformes (MEDINA FILHO et al., 2008).

Contudo, a utilização da embriogênese somática em plantas do gênero Coffea é um importante método de multiplicação in vitro, que consiste no desenvolvimento de embrióides a partir de células haplóides ou somáticas diplóides, sem que haja a fusão de gametas, e que possibilita micropropagação acelerada de clones superiores e a manutenção de híbridos interespecíficos (PEREIRA et al., 2007). Além disso, a embriogênese somática apresenta grande potencial para a multiplicação rápida e em larga escala de variedades selecionadas em uma ampla gama de espécies economicamente importantes (LANDEY et al., 2013).

Segundo Pereira et al. (2007), as auxinas e citocininas têm papel fundamental na embriogênese somática de várias espécies vegetais, a exemplo do cafeeiro, que é comum a adição do 6benzilaminopurina (BAP) para aumentar $\mathrm{o}$ crescimento da parte aérea de embriões somáticos em fase inicial de germinação. Porém, em algumas espécies torna-se necessário a suplementação do meio de cultura com ácido giberélico $\left(\mathrm{GA}_{3}\right)$ para o desenvolvimento de embriões somáticos, pois o $\mathrm{GA}_{3}$ participa de muitas atividades fisiológicas 
importantes, tendo efeito no crescimento, especialmente no alongamento caulinar.

Sendo assim, objetivou-se com este trabalho estabelecer protocolo para desenvolvimento e multiplicação in vitro de embriões somáticos e produção de mudas de Coffea arabica cultivar Acaiá Cerrado.

\section{MATERIAL E MÉTODOS}

Os experimentos foram conduzidos no Laboratório de Cultura de Tecidos Vegetais e em casa de vegetação do Departamento de Agricultura da Universidade Federal de Lavras, em Lavras, MG.

\section{Fase de cultivo in vitro}

No preparo dos meios de cultura foram utilizadas soluções estoque do meio MS (MURASHIGE; SKOOG, 1962) armazenadas em frascos de vidro escuro, à temperatura de aproximadamente $5^{\circ} \mathrm{C}$. $\mathrm{O} \mathrm{pH}$ do meio foi ajustado para $5,8 \pm 0,1$, com $\mathrm{NaOH} 0,5$ e $0,1 \mathrm{~N}$ ou $\mathrm{HCl} 0,1$ $\mathrm{N}$, antes da adição de $6 \mathrm{~g} \mathrm{~L}^{-1}$ de ágar. Os meios foram vertidos em tubos de ensaio $(25 \mathrm{~mm} \times 150$ $\mathrm{mm}$ ), vedados com tampas plásticas translúcidas e autoclavados à pressão de 1,1atm e à temperatura de $121^{\circ} \mathrm{C}$, durante 20 minutos.

Segmentos foliares retirados de plântulas de Coffea arabica cultivar Acaiá Cerrado foram introduzidos, em câmara de fluxo laminar horizontal desinfestada com álcool etílico a $70 \%$, em tubos de ensaio contendo $15 \mathrm{~mL}$ de meio de cultura para indução de embriões somáticos (PEREIRA et al., 2007). Os instrumentos (pinças e bisturis) foram autoclavados e periodicamente flambados, durante o seu uso, com álcool etílico hidratado $96^{\circ} \mathrm{GL}$. Logo após, os tubos de ensaio contendo os explantes foram mantidos em sala de crescimento, com temperatura de $25 \pm 1^{\circ} \mathrm{C}$.

\section{Avaliação dos experimentos}

Para a avaliação dos experimentos foram utilizadas: a) lupa estereoscópica, na determinação do número e estádios de desenvolvimento dos embriões, b) balança analítica de precisão, na determinação da massa fresca da parte aérea das plântulas e c) régua graduada, na determinação do comprimento da parte aérea das plântulas.

Os fatores dos experimentos foram analisados por meio de regressão polinomial, utilizando-se o programa estatístico SISVAR (FERREIRA, 2011).

Foi adotado o seguinte modelo estatístico: Yijk $=m+a i+b k+a b i k+$ eijk, em que, Yijk: valor observado na dose do fitorregulador $i$, dose do fitorregulador $\mathrm{k}$ e repetição j; m: média geral; ai: efeito da dose do fitorregulador i; bk: efeito da dose do fitorregulador k; abik: efeito da interação entre a dose do fitorregulador i e a dose do fitorregulador $k$; eijk: erro experimental na parcela $\mathrm{i}, \mathrm{j}, \mathrm{k}$.

\section{Desenvolvimento de embriões somáticos}

Embriões somáticos de Coffea arabica cv. Acaiá Cerrado foram mantidos durante 30 dias em meio MS com $100 \%$ dos sais, objetivando sua homogeneidade. Em seguida foram transferidos para meio MS com $50 \%$ dos sais acrescido de todas as combinações possíveis de $\operatorname{BAP}(0 ; 2,0 ; 4,0$ e $8,0 \mathrm{mg}$ $\left.\mathrm{L}^{-1}\right)$ e sacarose $\left(0 ; 30 ; 60 ; 90\right.$ e $\left.120 \mathrm{~g} \mathrm{~L}^{-1}\right), 100 \mathrm{mg} \mathrm{L}^{-}$ ${ }^{1}$ de caseína hidrolisada e $400 \mathrm{mg} \mathrm{L}^{-1}$ de extrato de malte.

Os embriões foram introduzidos in vitro individualmente em tubos de ensaio contendo 15 $\mathrm{mL}$ de meio de cultura e mantidos em sala de crescimento com irradiância em torno de $32 \mu \mathrm{M} \mathrm{m}^{-2}$ $\mathrm{s}^{-1}$, fotoperíodo de 16 horas e temperatura de $25 \pm 1$ ${ }^{\circ} \mathrm{C}$. O delineamento experimental utilizado foi inteiramente casualizado, em esquema fatorial $4 \times 5$, com quatro repetições de três tubos cada. Após 90 dias, o experimento foi avaliado em função de número de folhas, comprimento da parte aérea e massa fresca da parte aérea.

\section{Multiplicação}

Brotos de Coffea arabica cv. Acaiá Cerrado oriundos de plântulas provenientes de embriões somáticos obtidos por via direta, foram seccionados com 1 a $1,5 \mathrm{~cm}$ de comprimento estabelecidos in vitro durante 60 dias em meio MS com $100 \%$ dos sais e acrescido de $8 \mathrm{mg} \mathrm{L}^{-1}$ de BAP, objetivando sua homogeneidade. Em seguida foram transferidos para meio MS 50\% acrescido de todas as combinações possíveis de $\mathrm{GA}_{3}(0 ; 2,5 ; 5,0 ; 10,0$ e $\left.20,0 \mathrm{mg} \mathrm{L}^{-1}\right)$ e ANA $\left(0 ; 0,25 ; 0,50 ; 1,0 \mathrm{mg} \mathrm{L}^{-1}\right)$.

Os explantes foram introduzidos in vitro individualmente em tubos de ensaio contendo 15 $\mathrm{mL}$ de meio de cultura e mantidos em sala de crescimento com irradiância em torno de $32 \mu \mathrm{M} \mathrm{m}^{-2}$ $\mathrm{s}^{-1} \mathrm{e}$ fotoperíodo de 16 horas e temperatura de $25 \pm 1$ ${ }^{\circ} \mathrm{C}$. O delineamento experimental utilizado foi inteiramente casualizado, em esquema fatorial $5 \times 4$, com quatro repetições de três tubos cada. Após 60 dias, o experimento foi avaliado em função de número de folhas, comprimento da parte aérea e massa fresca da parte aérea.

\section{Enraizamento e aclimatização de plântulas} Após o período de multiplicação, segmentos nodais foram inoculados em meio MS com 100\% dos sais, suplementado com diferentes 
concentrações de $\operatorname{AIB}\left(0,10\right.$ e $\left.50 \mathrm{mg} \mathrm{L}^{-1}\right)$. Os explantes permaneceram em sala de crescimento por 35 dias e, após este período, foram divididos em três tratamentos: 1) plântulas com raízes, oriundas de meio 'MS + AIB $10 \mathrm{mg} \mathrm{L}^{-1}$ ' (CRAIB), 2) plântulas sem raízes, oriundas de meio 'MS' (SR-MS) e plântulas imersas em solução contendo AIB na concentração de $50 \mathrm{mg} \mathrm{L}^{-1}$ por 20 horas (SR-AIB).

Após o tratamento, foram transferidas para bandejas de isopor contendo Plantmax hortaliçasT como substrato e mantidos em casa de vegetação. $\mathrm{O}$ fornecimento de minerais foi feito por meio da aplicação semanal de $1 \mathrm{~mL}$ do meio MS líquido, com $100 \%$ dos sais por plântula, iniciado no dia do plantio e estendendo-se até o final do experimento.

$\mathrm{O}$ delineamento experimental utilizado foi inteiramente casualizado, com quatro repetições e cinco plantas por parcela. Os dados foram submetidos à análise estatística.

Após a análise de variância, as médias foram comparadas pelo teste de Tukey. Foi adotado o seguinte modelo estatístico: $Y i j=m+a i+e i j$, em que, Yij: valor observado na parcela para o tratamento i na repetição j; m: média geral; ai: efeito do tratamento i; eij: erro experimental na parcela $\mathrm{i}, \mathrm{j}$.
Após 80 dias, as plântulas foram avaliadas em função das seguintes variáveis: número de pares de folhas, comprimento da parte aérea, comprimento da maior raiz e massa fresca total.

\section{RESULTADOS E DISCUSSÃO}

\section{Desenvolvimento de embriões somáticos}

Através da análise de variância, verificou-se para as características número de folhas, comprimento da parte aérea e massa fresca de parte aérea de plântula de $C$. arábica $\mathrm{cv}$. Acaiá Cerrado interação significativa entre os fatores sacarose e BAP analisados em nível de $1 \%$ de probabilidade.

\section{Número de folhas}

$\mathrm{O}$ maior número de folhas $(3,8)$ foi obtido com 5,9 mg L $\mathrm{mg}^{-1}$ de BAP associado a $90 \mathrm{~g} \mathrm{~L}^{-1}$ de sacarose (Figura 1). A partir desse ponto houve redução, provavelmente devido à elevação do potencial osmótico no meio de cultura. A alta concentração de sacarose afeta a assimilação de nutrientes e o efeito de reguladores de crescimento (PASQUAL, 2001).

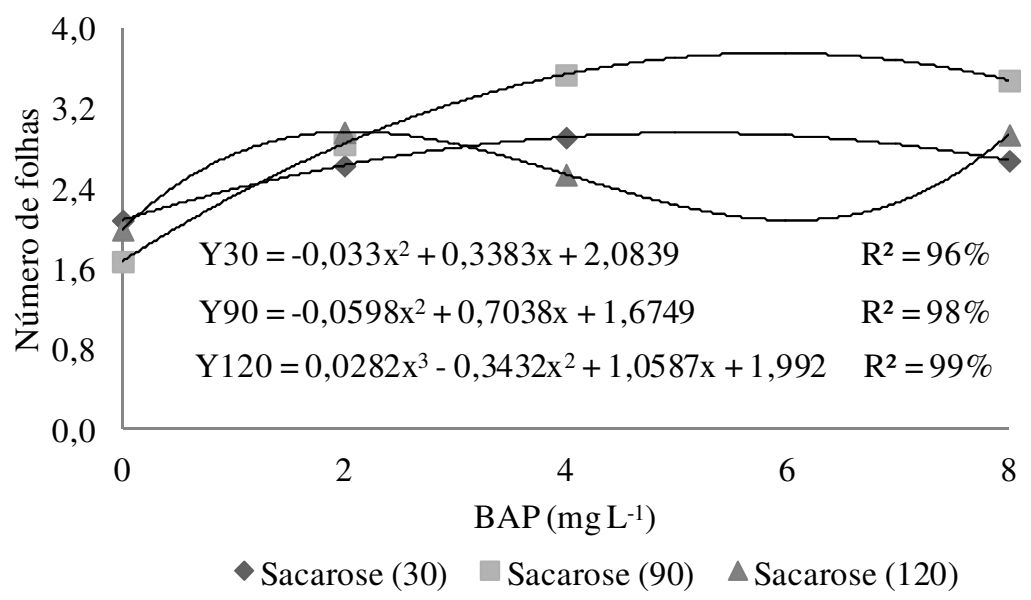

Figura 1. Efeito de concentrações de BAP e sacarose no número de folhas da C. arabica cv. Acaiá Cerrado.

Segundo Sharp et al. (1980), a concentração de sacarose é um fator importante para o cultivo de embriões e, na fase de desenvolvimento, estes necessitam de concentrações elevadas de sacarose (90 a $\left.120 \mathrm{~g} \mathrm{~L}^{-1}\right)$. À medida que aumentaram as concentrações de BAP, até a concentração de 5,9 $\mathrm{mg} \mathrm{L}^{-1}$, combinadas às concentrações de $30 \mathrm{e} 90 \mathrm{~g}$ $\mathrm{L}^{-1}$ de sacarose, um incremento no número de folhas foi observado (Figura 1). Porém, Hu; Ferreira (1998) afirmam que os reguladores de crescimento não necessitam ser adicionados ao meio de cultura de embriões, exceto quando o objetivo do trabalho é a multiplicação rápida. Em contrapartida, Ribeiro et al. (2003), estudando o cultivo in vitro de embriões zigóticos de $C$. arabica cv. Catuaí Vermelho obtiveram os melhores resultados para número de folhas quando adicionaram ao meio de cultura 7,4 $\mathrm{mg} \mathrm{L}^{-1}$ de BAP.

\section{Comprimento da parte aérea}

Maior comprimento da parte aérea $(2,78$ $\mathrm{cm}$ ) foi obtido com $2 \mathrm{mg} \mathrm{L}^{-1}$ de BAP associado a 90 $\mathrm{g} \mathrm{L}^{-1}$ de sacarose, observando-se menores valores quando foram utilizadas concentrações entre 2,1 e 6 
$\mathrm{mg} \mathrm{L}^{-1}$ de BAP (Figura 2). Esses resultados estão de acordo com Pasqual (2001), que comenta que altas concentrações de citocininas podem reduzir o comprimento das brotações e estimular a ocorrência de vitrificação.

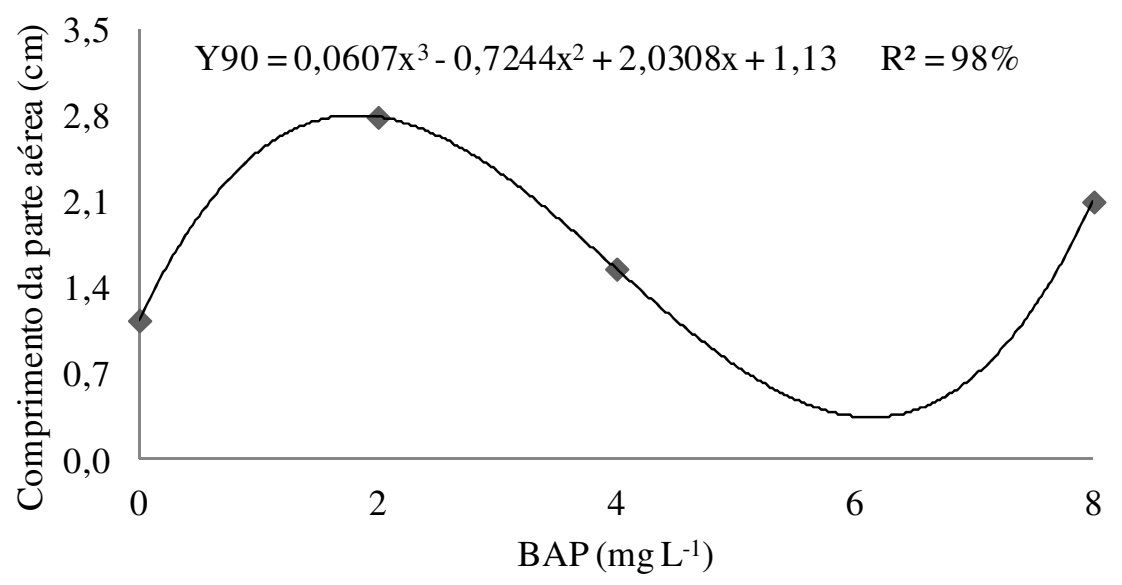

- Sacarose (90)

Figura 2. Efeito de concentrações de BAP e sacarose no comprimento da parte aérea de embriões somáticos da C. arabica cv. Acaiá Cerrado.

\section{Massa fresca da parte aérea}

À medida que aumentaram as concentrações de BAP, na ausência de sacarose, maior massa fresca da parte aérea $(1,14 \mathrm{~g})$ foi observada (Figura 3). Utilizando-se $30 \mathrm{~g} \mathrm{~L}^{-1}$ de sacarose podem-se observar menores valores quando foram adicionadas concentrações mais altas do fitorregulador. Segundo $\mathrm{Hu}$; Ferreira (1998), de maneira geral, quanto mais jovem for o embrião, mais alta será a osmolaridade requerida do meio de cultura e, na maturidade, o embrião pode crescer em meio de cultura desprovido de sacarose.

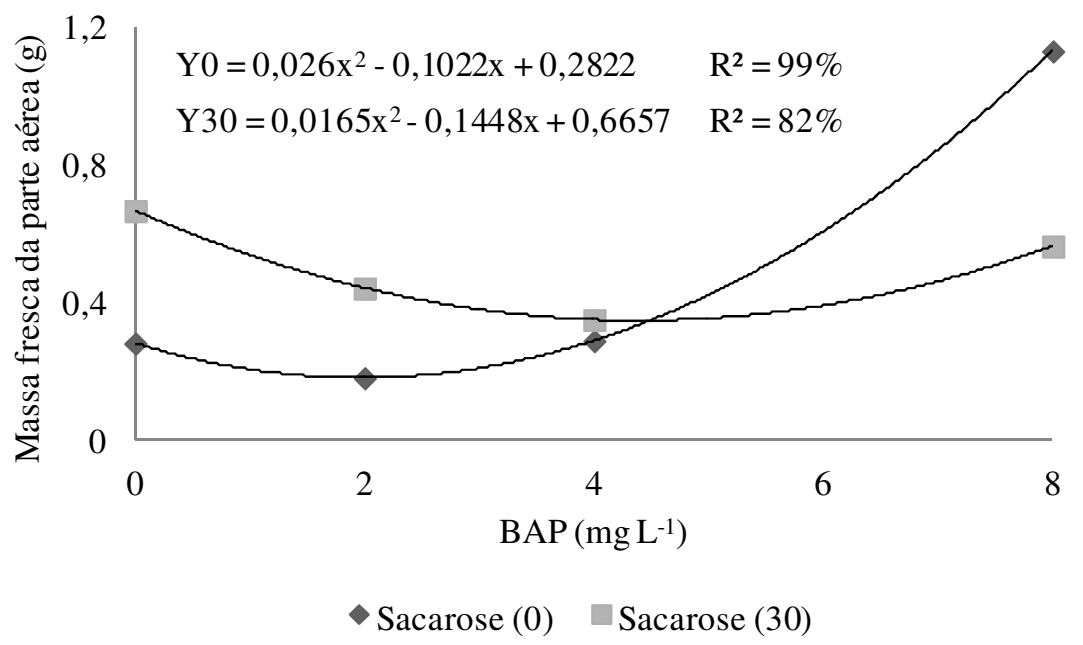

Figura 3. Efeito de concentrações de BAP e sacarose na massa fresca da parte aérea de embriões somáticos da C. arabica cv. Acaiá Cerrado.

\section{Multiplicação de plântulas de cafeeiro}

Através da análise de variância para as características número de folhas, comprimento da parte aérea e massa fresca de parte aérea de plântula de C. arábica cv. Acaiá Cerrado observou-se interação significativa entre os fatores sacarose e BAP analisados em nível de $1 \%$ de probabilidade.
Verificou-se, por meio da análise de variância, interação significativa a $1 \%$ de probabilidade entre os reguladores de crescimento $\mathrm{GA}_{3}$ e ANA para as variáveis número de folhas e comprimento da parte aérea de plântulas de $C$. arabica cv. Acaiá Cerrado. 


\section{Número de folhas}

Maior número de folhas $(7,1)$ foi obtido quando foram utilizados $11,5 \mathrm{mg} \mathrm{L}^{-1}$ de $\mathrm{GA}_{3}$ na ausência de ANA (Figura 4). A partir desse ponto houve redução no número de folhas, provavelmente devido ao efeito fitotóxico desse regulador de crescimento. Na concentração de $0,5 \mathrm{mg} \mathrm{L}^{-1}$ de
RODRIGUES, A. R. P. et al.

ANA na ausência de $\mathrm{GA}_{3}$, obtiveram-se explantes com 7 folhas. Como não há diferença significativa no número de folhas, justifica-se utilizar $0,5 \mathrm{mg} \mathrm{L}^{-1}$ de ANA, que é o regulador de crescimento de menor custo. Na concentração de $0,25 \mathrm{mg} \mathrm{L}^{-1}$ de ANA, combinada com $5 \mathrm{mg} \mathrm{L}^{-1}$ de $\mathrm{GA}_{3}$, foram observadas 6 folhas.

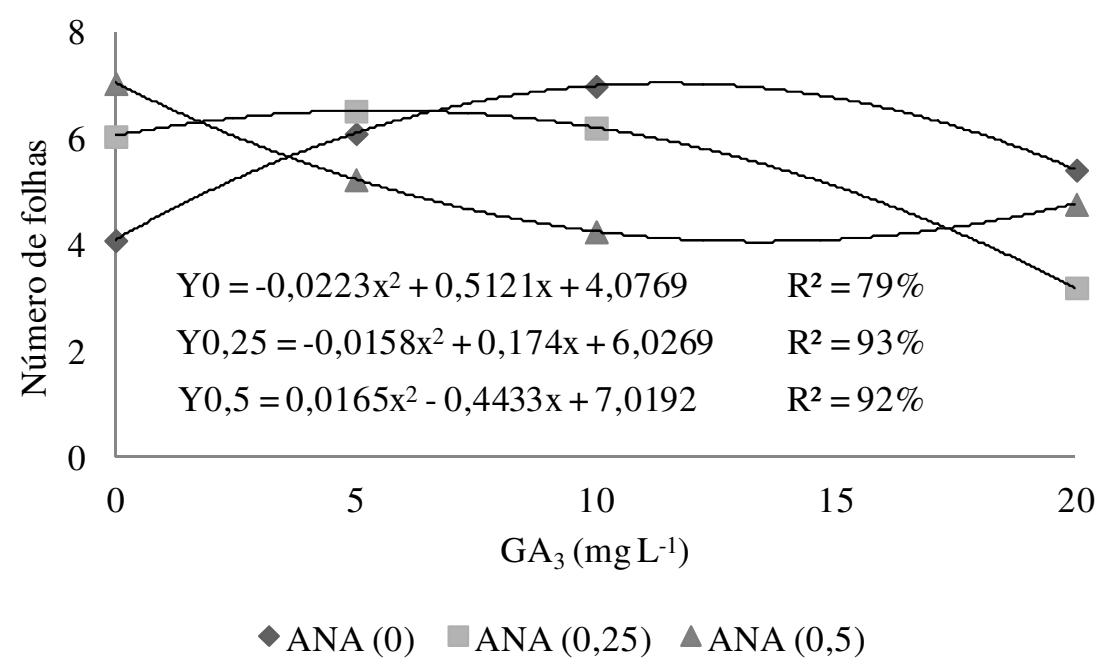

Figura 4. Efeito de concentrações de $\mathrm{ANA}$ e $\mathrm{GA}_{3}$ no número de folhas de plântulas de $C$. arabica cv. Acaiá Cerrado.

Já Andrade et al. (2001), trabalhando com embriões zigóticos de Coffea arabica cv. Catuaí Vermelho, observaram melhores resultados para o número de folhas com a utilização de $1 \mathrm{mg} \mathrm{L}^{-1}$ de ANA.
Altas concentrações de GA3, independentemente das concentrações de ANA, proporcionaram folhas alongadas, estreitas $\mathrm{e}$ retorcidas (Figura 5).

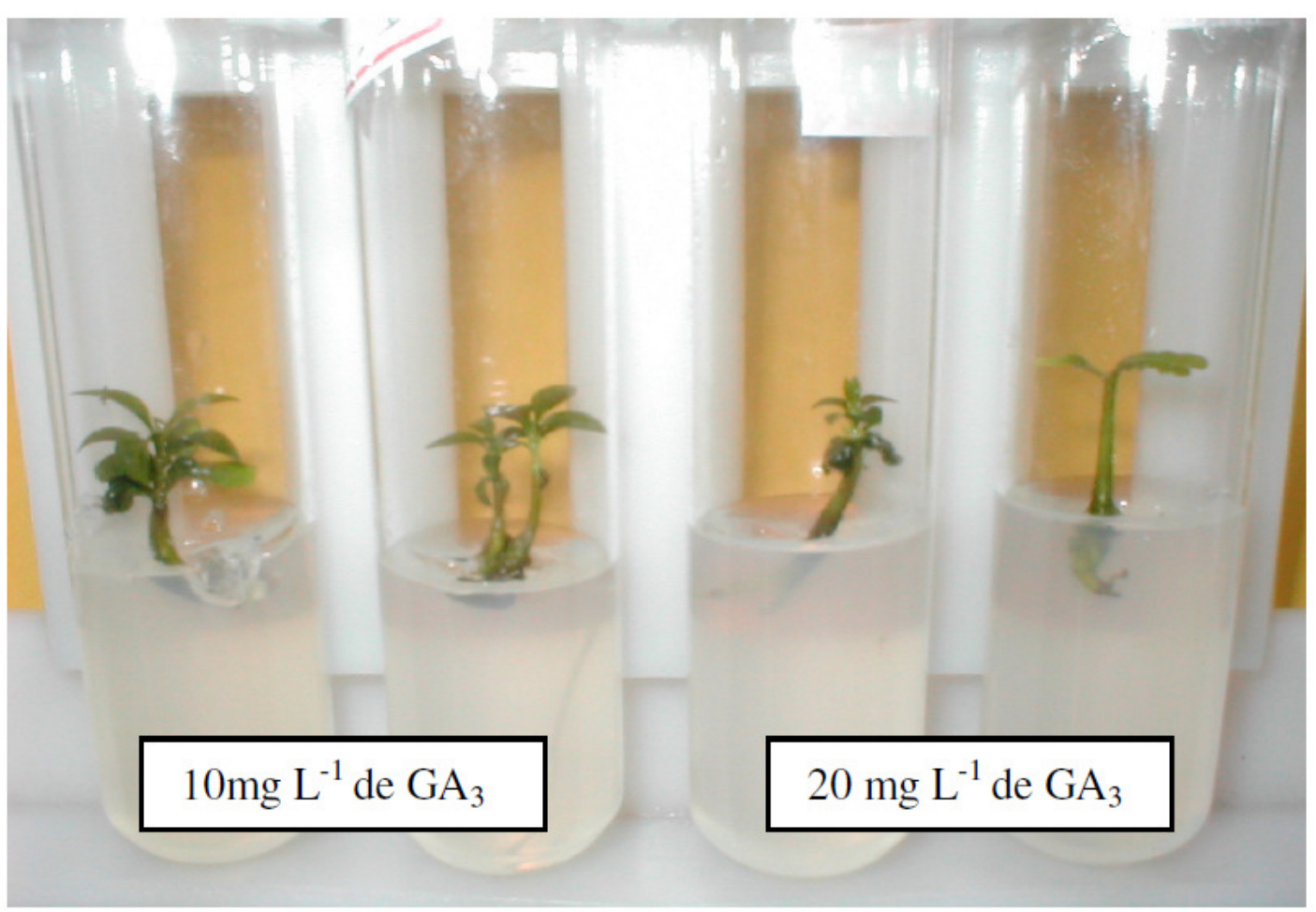

Figura 5. Efeito de diferentes concentrações de $\mathrm{GA}_{3}$ em plântulas de cafeeiro cv. Acaía Cerrado. 


\section{Comprimento da parte aérea}

Melhor resultado para comprimento da parte aérea $(2,75 \mathrm{~cm})$ foi obtido com a utilização de 0,5 $\mathrm{mg} \mathrm{L}^{-1}$ de ANA e 14,2 $\mathrm{mg} \mathrm{L}^{-1}$ de $\mathrm{GA}_{3}$ (Figura 6).

Entretanto, na ausência de ANA associada a $20 \mathrm{mg} \mathrm{L}^{-1}$ de $\mathrm{GA}_{3}$ obtiveram-se plântulas de cafeeiro com 2,55 cm. O incremento das concentrações de $\mathrm{GA}_{3}$ na ausência de ANA promoveu aumento no comprimento da parte aérea. Por outro lado, Andrade et al. (2001) obtiveram melhor resultado para comprimento da parte aérea de Coffea arabica cv. Catuaí Vermelho quando adicionaram, ao meio de cultura, $1 \mathrm{mg} \mathrm{L}^{-1}$ de ANA.

Observa-se que, com a concentração de 0,5 mg $\mathrm{L}^{-1}$ de ANA, houve um decréscimo no comprimento de plântulas com a adição de concentrações superiores a $14,5 \mathrm{mg} \mathrm{L}^{-1}$ de $\mathrm{GA}_{3}$, provavelmente, devido ao efeito fitotóxico desse regulador.

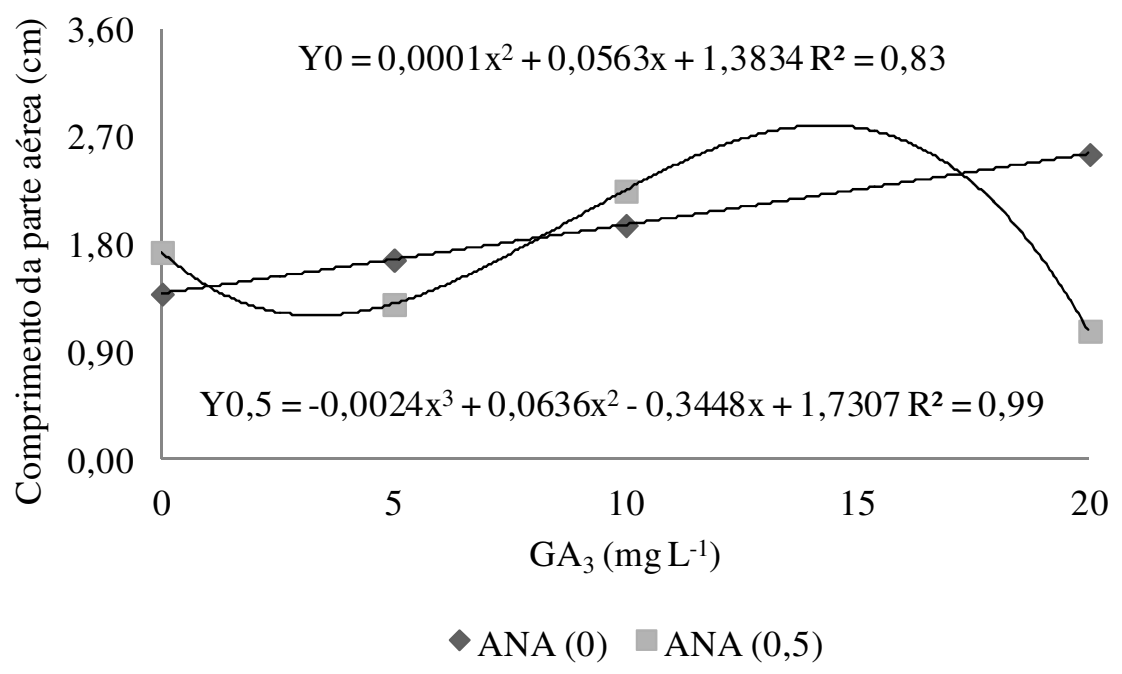

Figura 6. Efeito de concentrações de ANA e $\mathrm{GA}_{3}$ no comprimento da parte aérea de plântulas de C. arabica cv. Acaiá Cerrado.

Há poucos relatos da obtenção de embriogênese somática direta em $C$. arabica. Entretanto, C. canephora tem sido utilizada como espécie modelo para o emprego dessa técnica. Esta diferença de resposta entre espécies, aliada à baixa frequência de formação de embriões, indica que alguns problemas ainda precisam ser resolvidos antes do uso prático da micropropagação via embriogênese direta em cafeeiro. Portanto, para a utilização em larga escala, pesquisas ainda são necessárias para desenvolver protocolos de embriogênese direta que permitam aumentar a amplitude de genótipos capazes de produzir embriões somáticos em alta frequência e estabilidade genética do genótipo do doador.

\section{Massa fresca da parte aérea}

Para a variável massa fresca da parte aérea de plântulas, houve efeito significativo apenas para o efeito isolado do ANA, contudo, não ocorreram interação significativa entre as concentrações de ANA e $\mathrm{GA}_{3}$ e significância para efeito isolado do $\mathrm{GA}_{3}$. Melhor resultado $(0,079 \mathrm{~g})$ foi verificado quando se utilizou $0,75 \mathrm{mg} \mathrm{L}^{-1}$ de ANA (Figura 7), entretanto, na ausência desse mesmo fitorregulador, foram obtidos $0,060 \mathrm{~g}$. Nesse caso, justifica-se utilizar o meio de cultura com a ausência do fitoregulador ANA, com o objetivo de redução de custos. Já Andrade et al. (2001), estudando embriões zigóticos de Coffea arabica cv. Catuaí Vermelho, obtiveram melhores resultados para massa fresca com a adição de $0,53 \mathrm{mg} \mathrm{L}^{-1}$ de ANA ao meio de cultura.

\section{Aclimatização de plântulas \\ Presença ou ausência de raízes na aclimatização de plântulas}

Houve efeito significativo apenas para a variável massa fresca total, porém as variáveis número de pares de folhas, comprimento da parte aérea e comprimento da maior raiz não apresentaram diferença significativa. Isso implica que a utilização de $\mathrm{AIB}$, ex vitro ou in vitro, para o enraizamento de plântulas de cafeeiro, é desnecessária para incrementar o crescimento e o desenvolvimento da parte aérea e raízes. Observouse que houve $100 \%$ de enraizamento em todos os tratamentos testados (Figura 8). Esse 
comportamento está de acordo com Carvalho et al. (1999) que, estudando a aclimatização de cafeeiro cv. Acaiá observou que não havia necessidade do enraizamento in vitro com a utilização de AIB.

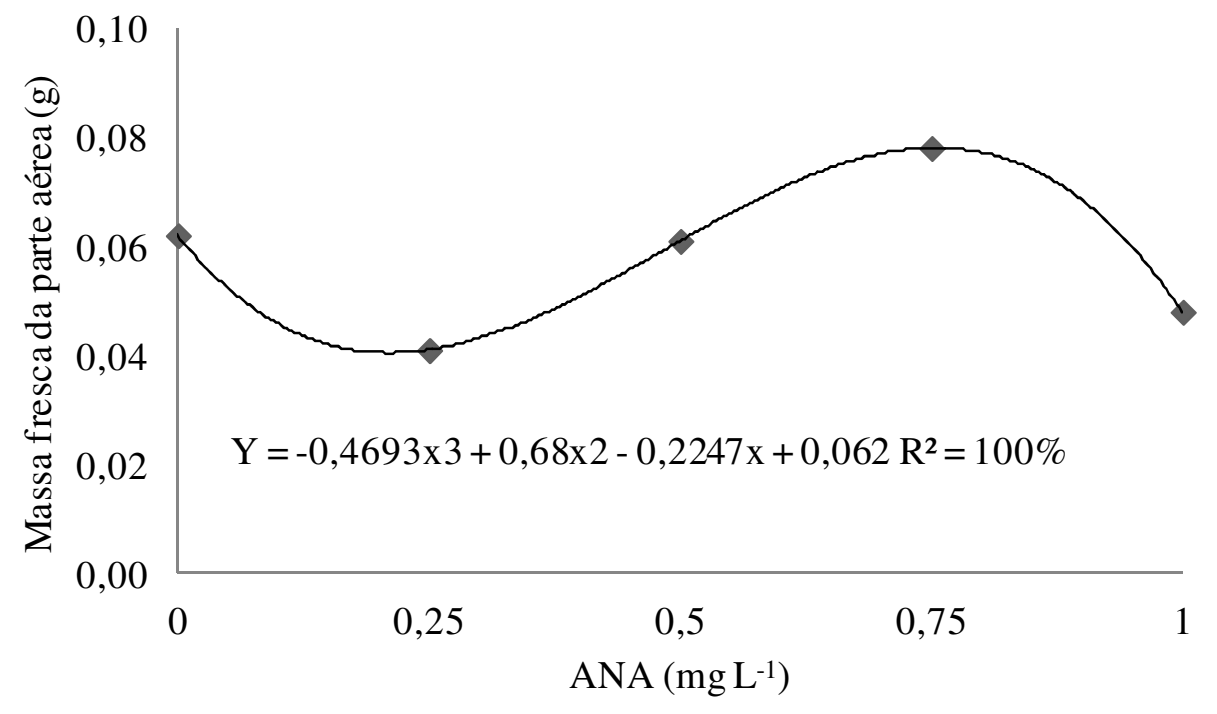

Figura 7. Efeito de concentrações de ANA na massa fresca da parte aérea de plântulas de C. arabica cv. Acaiá Cerrado.

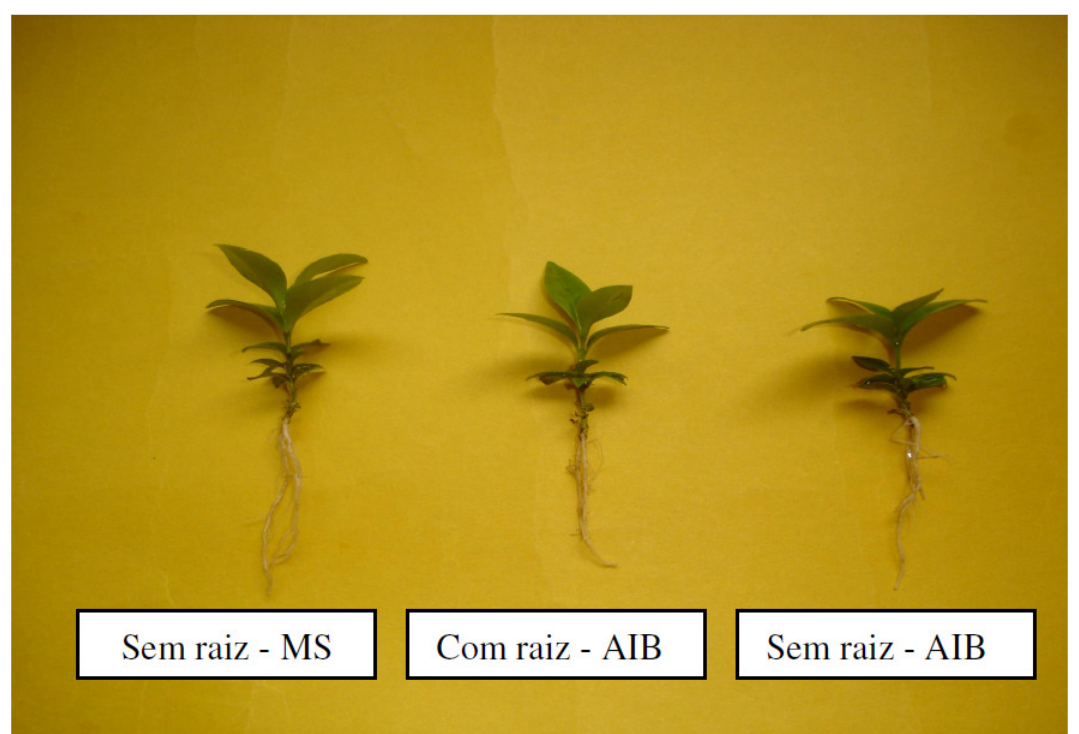

Figura 8. Efeito de AIB e presença ou ausência de raízes de plântulas de C. arabica cv. Acaiá Cerrado.

Segundo George (1996), apesar do interesse para a aclimatização de plântulas enraizadas in vitro, tem-se observado que as raízes formadas nesta condição não se tornam suficientemente desenvolvidas para estimular o crescimento de plantas lenhosas. Além disso, o enraizamento in vitro é extremamente indesejável sob o aspecto econômico, pois o gasto nessa fase apenas se justifica caso este resulte em plântulas de melhor qualidade final ou se perdas durante a aclimatização puderem ser reduzidas.

\section{Massa fresca total}

Melhor resultado para massa fresca total $(0,341 \mathrm{~g})$ foi obtido quando aclimatizaram-se brotações sem raízes (Tabela 1). Provavelmente, devido à regeneração de raízes diretamente no substrato, tende-se a produzir um sistema radicular mais completo e funcional. Porém, o sistema radicular formado in vitro é, em geral, pouco ramificado, quebradiço e isento de pêlos radiculares, 
o que dificulta a absorção de água e nutrientes

durante a aclimatização.

Tabela 1. Efeito de AIB e presença ou ausência de raízes na massa fresca total de plântulas de C. arabica cv. Acaiá Cerrado.

\begin{tabular}{cc}
\hline Tratamentos & Massa fresca total $(\mathrm{g})$ \\
\hline SR-MS (sem raiz +MS) & $0,341 \mathrm{a}$ \\
CR-AIB (com raiz + AIB) & $0,273 \mathrm{~b}$ \\
SR-AIB (sem raiz + AIB) & $0,202 \mathrm{c}$ \\
\hline
\end{tabular}

Médias seguidas pela mesma letra não diferem significativamente entre si pelo teste de Tukey, a 5\% de probabilidade.

$\mathrm{O}$ enraizamento in vitro ou ex vitro, com a utilização de AIB, não contribuiu para o incremento de massa fresca total de plântulas de cafeeiro cv. Acaiá Cerrado. Embora o AIB seja a auxina mais utilizada na indução de enraizamento, misturas de diferentes auxinas têm apresentado melhores resultados do que quando utilizadas isoladamente (ASSIS; TEIXEIRA, 1998). Segundo Carvalho et al. (1999), a imersão de brotações de cafeeiro em solução contendo AIB prejudica o desenvolvimento das plântulas durante a fase de aclimatização.

\section{CONCLUSÕES}

É possível a obtenção de plântulas micropropagadas de Coffea arabica L. cultivar Acaiá Cerrado pela embriogênese somática direta.

$\mathrm{O}$ enraizamento de brotações de cafeeiro cv. Acaiá Cerrado ocorre simultaneamente ao processo de aclimatização.

A utilização do AIB, na fase de enraizamento in vitro ou ex vitro, não contribuiu para o incremento de massa fresca total de plântulas de cafeeiro cv. Acaiá Cerrado.

\begin{abstract}
An important method of in vitro plant's multiplication of Coffea is somatic embryogenesis, which consists in developing embryoid from haploid or diploid somatic cells, without the fusion of gametes allowing the accelerated micropropagation and maintenance of superior clones interspecific hybrids. However there are few reports of direct embryogenesis in Coffea arabica. The objective of this work to establish protocol for in vitro development of somatic embryos and seedlings of $C$. arabica Acaiá Cerrado. The influence of sucrose $\left(0,30,60,90\right.$ and $\left.120 \mathrm{~g} \mathrm{~L}^{-1}\right) \times$ BAP $\left(0,2,4\right.$ and $\left.8 \mathrm{mg} \mathrm{L}^{-1}\right)$ on somatic embryos from embryogenic were evaluated. In seedling development, NAA $(0,0.25,0.5$ and $\left.1 \mathrm{mg} \mathrm{L}^{-1}\right) \times \mathrm{GA}_{3}\left(0,2.5,5.0,10\right.$ and $\left.20 \mathrm{mg} \mathrm{L}^{-1}\right)$ in shoots were tested, with average size of 1 to $1.5 \mathrm{~cm}$, derived from somatic embryos in vitro. During the development stage of embryos and embryonic seedling induction, the experiment was conducted in a growth chamber under conditions of darkness and the stage of development of embryos and seedlings, the explants were subjected to irradiation around $32 \mathrm{mM} \mathrm{m}^{-2} \mathrm{~s}^{-1}$ and a photoperiod of 16 hours at a temperature of $25 \pm 1^{\circ}$ C. In acclimatization, the effect of the presence and absence of roots in coffee seedlings originating from direct somatic embryogenesis were evaluated. The addition of $90 \mathrm{~g} \mathrm{~L}^{-1}$ sucrose and $2 \mathrm{mg} \mathrm{L}^{-1} \mathrm{BAP}$ to the culture medium provides a better in vitro growth of embryos from coffee. Using $0.5 \mathrm{mg} \mathrm{L}^{-1} \mathrm{NAA}$ and $14.2 \mathrm{mg} \mathrm{L}^{-1} \mathrm{GA}_{3}$ obtains greater shoot length of shoots of $C$. arabica L. cv. Acaiá Cerrado. It was concluded that it is possible to obtain plantlets C. arabica L. Acaiá Cerrado by direct somatic embryogenesis. The rooting of shoots of coffee Acaiá Cerrado occurs simultaneously with the process of acclimatization.
\end{abstract}

KEYWORDS: Somatic embryos. Coffee. Acclimatization.

\title{
REFERÊNCIAS
}

ANDRADE, L. M. da C.; PASQUAL, M.; MACIEL, A. L. de R.; PEREIRA, A. B.; CAVALCANTE-ALVES, J. M. Cultura in vitro de embriões de Coffea arabica: influência de NAA e BAP. Ciência e Agrotecnologia, Lavras, v. 25, n. 5, p. 1063-1070, 2001.

ASSIS, T. F.; TEIXEIRA, S. L. Enraizamento de plantas lenhosas. In: TORRES, A.; CALDAS, L. S.; BUSO, J. A. (Ed.). Cultura de tecidos e transformação genética de plantas. Brasília-DF: Embrapa/CNPH, 1998. v. 1, p. 183-260.

CARVALHO, G. R.; PASQUAL, M.; RESENDE, E.; SCARANTE, M. J. Aclimatização de plântulas de cafeeiro (Coffea arabica L.) propagadas in vitro. Ciência e Agrotecnologia, Lavras, v. 23, n. 3, p. 483-490, 1999. 
DAVIS, A. P. Six species of Psilanthus transferred to Coffea (Coffeeae, Rubiaceae). Phytotaxa, v. 10, p. 4145, 2010. http://dx.doi.org/10.11646/phytotaxa.10.1.6

DAVIS, A. P. Psilanthus mannii, the type species of Psilanthus, transferred to Coffea. Nordic Journal of Botany, v. 29, p. 471-472, 2011. http://dx.doi.org/10.1111/j.1756-1051.2011.01113.x

DAVIS, A. P.; GOVAERTS, R.; BRIDSON, D. M.; STOFFELEN, P. An annotated taxonomic conspectus of the genus Coffea (Rubiaceae). Botanical Journal of the Linnean Society, v. 142, p. 465-512, 2006.

http://dx.doi.org/10.1111/j.1095-8339.2006.00584.x

DAVIS, A. P.; RAKOTONASOLO, F.; DEBLOCK, P. Coffea toshii sp. nov. (Rubiaceae) from Madagascar. Nordic Journal of Botany, v. 28, p. 134-136, 2010. http://dx.doi.org/10.1111/j.1756-1051.2010.00710.x

DAVIS, A. P.; TOSH, J.; RUCH, N.; FAY, M. Growing coffee: Psilanthus (Rubiaceae) subsumed on the basis of molecular and morphological data; implications for the size, morphology, distribution and evolutionary history of Coffea. Botanical Journal of the Linnean Society, v. 167, p. 357-377, 2011.

http://dx.doi.org/10.1111/j.1095-8339.2011.01177.x

FERREIRA, D. F. SISVAR: A computer statistical analysis system. Ciência e Agrotecnologia, Lavras, v. 35, n. 6, p. 1039-1042, 2011.

GEORGE, E. F. Plant propagation by tissue culture, part 1 - The technology. 2. ed. Edington, 1996. 1574 p.

HU, C. Y.; FERREIRA, A. G. Cultura de embriões. In: TORRES, A.; CALDAS, L. S.; BUSO, J. A. (Ed.).

Cultura de tecidos e transformação genética de plantas. Brasília-DF: Embrapa, 1998. v. 1, p. 371-393.

LANDEY, R. B.; CENCI, A.; GEORGET, F.; BERTRAND, B.; CAMAYO, G.; DECHAMP, E.; HERRERA, J. C.; SANTONI, S.; LASHERMES, P.; SIMPSON, J.; ETIENNE, H. High genetic and epigenetic stability in Coffea arabica plants derived from embryogenic suspensions and secondary embryogenesis as revealed by AFLP, MSAP and the phenotypic variation rate. PLoS One, v. 8, n. 2, p. 1-15, 2013.

MEDINA FILHO, H. P.; BORDIGNON, R.; CARVALHO, C. H. S. Desenvolvimento de novas cultivares de café arábica (Ed). In: CARVALHO, C. H. S. Cultivares de café: origem, características e recomendação: Brasília: Embrapa Café, 2008. v. 1, p. 79-102.

MURASHIGE, T.; SKOOG, F. A revised medium for rapid growth and biossay with tobacco tissue culture. Physiologia Plantarum, Copenhagen, v. 15, n. 3, p. 473-497, 1962. http://dx.doi.org/10.1111/j.1399-

3054.1962.tb08052.x

PASQUAL, M. Meios de cultura. In: PASQUAL, M. Cultura de tecidos vegetais. Lavras: UFLA/FAEPE, 2001. v. 1, p. 71 .

PEREIRA, A. R.; CARVALHO, S. P. de; PASQUAL, M .; SANTOS, F. C. Embriogênese somática direta de explantes foliares de Coffea arabica L. cv. Acaiá Cerrado: efeito de cinetina e ácido giberélico. Ciência e Agrotecnologia, Lavras, v. 31, n. 2, p. 332-336, 2007.

RIBEIRO, L. S.; PASQUAL, M.; MACIEL, A. L. R.; CHAGAS, E. A.; DUTRA, L. F. Desenvolvimento in vitro de embriões zigóticos de Coffea arabica. Ciência e Agrotecnologia, Lavras, v. 27, p. 1479-1483, 2003.

SHARP, W. R.; SONDAHL, M.; CALDAS, L. S.; MARAFFA, S. B. The physiology on in vitro assexual embryogenesis. Horticultural Review, New York, v. 2, p. 268-310, 1980. 